\title{
Influence of Family History of Breast or Ovarian Cancer on Pathological Complete Response and Long-Term Prognosis in Breast Cancer Patients Treated with Neoadjuvant Chemotherapy
}

\author{
Marius Wunderle $^{a}$ Lothar Häberle ${ }^{a, b} \quad$ Alexander Hein $^{a} \quad$ Sebastian M. Jud ${ }^{a}$ \\ Michael P. Lux ${ }^{c}$ Carolin C. Hack $^{\mathrm{a}} \quad$ Julius Emons ${ }^{\mathrm{a}}$ Felix Heindl ${ }^{\mathrm{a}}$ \\ Naiba Nabieva $^{a} \quad$ Christian R. Loehberg $^{a}$ Rüdiger Schulz-Wendtland ${ }^{d}$ \\ Arndt Hartmann ${ }^{\text {e }}$ Matthias W. Beckmann ${ }^{a}$ Peter A. Fasching ${ }^{a}$ Paul Gass ${ }^{a}$ \\ ${ }^{a}$ Department of Gynecology and Obstetrics, Erlangen University Hospital, Comprehensive Cancer Center \\ Erlangen-EMN, Friedrich Alexander University of Erlangen-Nuremberg, Erlangen, Germany; ${ }^{\mathrm{b}}$ Biostatistics Unit, \\ Department of Gynecology and Obstetrics, Erlangen University Hospital, Friedrich Alexander University of \\ Erlangen-Nuremberg, Erlangen, Germany; ' Department of Gynecology and Obstetrics, Women's Hospital St. Louise \\ Paderborn, Women's Hospital St. Josefs-Krankenhaus Salzkotten, Frauen- und Kinderklinik St. Louise, Paderborn, \\ Germany; ${ }^{d}$ Institute of Diagnostic Radiology, Erlangen University Hospital, Friedrich Alexander University of \\ Erlangen-Nuremberg, Erlangen, Germany; ${ }^{\mathrm{e}}$ Institute of Pathology, Erlangen University Hospital, \\ Friedrich Alexander University of Erlangen-Nuremberg, Erlangen, Germany
}

\section{Keywords}

Breast cancer - Ovarian cancer · Family history . Neoadjuvant chemotherapy · Pathological complete response $\cdot$ Prognosis

\section{Abstract}

Purpose: In breast cancer, a pathological complete response $(\mathrm{pCR})$ has been described as generally resulting in a favorable prognosis. However, there are subgroups, such as patients with a mutation in $B R C A 1$ or $B R C A 2$, in which the effect of $\mathrm{pCR}$ on the prognosis is suspected to be weaker. Patients with a family history of breast and/or ovarian cancer may therefore react differently in relation to $\mathrm{pCR}$ and prognosis, and this is investigated in this study. Patients and Methods: Breast cancer patients were identified from a clinical breast cancer registry. The study subjects had been treated with neoadjuvant chemotherapy from 2001 to 2018 and their
}

pathological and clinical information as well as medical family history were available. They were considered to have a positive family history if they had at least 1 first-degree relative with breast and/or ovarian cancer. Multivariate logistic regression analyses were performed to study the association between family history, pCR (ypT0; ypN0), and disease-free survival (DFS). Results: Of 1,480 patients, 228 (15.4\%) had a positive family history. The $\mathrm{pCR}$ rates were $24.9 \%$ in all patients, and $24.4 \%$ and $27.6 \%$ in those without/with a family history, respectively. Family history was not associated with a higher pCR rate (adjusted odds ratio [OR] 1.23; 95\% confidence interval $[\mathrm{Cl}] 0.85-1.76 ; p=0.27)$ or a different diseasefree survival (DFS; adjusted hazard ratio [HR] 1.15; $95 \% \mathrm{Cl}$ $0.88-1.52 ; p=0.30)$. pCR did not affect the prognosis differently in relation to family history. Conclusions: In this retrospective analysis, family history was not associated with $\mathrm{PCR}$ and DFS. pCR improved survival, independently of family history. (c) 2020 S. Karger AG, Basel 


\section{Introduction}

With the aim of individualizing treatments for patients with breast cancer (BC), recent studies have been focusing on molecular and genetic subgroups in $\mathrm{BC}$ as well as on neoadjuvant therapy. The neoadjuvant setting appears to be ideal for learning about the response pattern of tumors as well as for investigating the predictors of tumor response $[1,2]$. Certain factors have been identified that predict the pathological complete response (pCR) very consistently across studies. These include hormone receptor status, HER2 receptor status, grading, tumor proliferation (Ki-67), tumor stage, and intrinsic molecular subtypes of BC. Other factors such as age, body mass index (BMI), familial or genetic background, and other patient characteristics are under discussion [1,3-6]. Germline BRCA1/2 mutations have been associated with better pCR rates across different studies [7-12]. This treatment effect appears to be most prominent in patients with triple-negative breast cancer (TNBC) when platinum chemotherapies are used [8-11].

pCR generally correlates very well with an excellent prognosis in patients with HER2 receptor-positive, hormone receptor-negative and triple-negative $\mathrm{BC}[1,2,6$, $13,14]$. In hormone receptor-positive, low-grade $\mathrm{BC}$, the $\mathrm{pCR}$ rate is lower and the association with a favorable prognosis is not as clear [14]. With regard to BRCA1/2 mutation carriers, some studies have demonstrated improved survival in patients with a pCR $[10,11,15]$. However, a small-scale study reported that in BRCA1 mutation carriers with TNBC, pCR may not be predictive of prognosis [7]. Another analysis from the GeparQuinto Trial confirmed that $\mathrm{pCR}$ is a strong predictor of diseasefree survival (DFS) in patients without $B R C A 1 / 2$ mutations, but not in patients with BRCA1/2 mutations [12].

It is therefore important to understand in which group of patients $\mathrm{pCR}$ translates clearly into a long-term survival benefit, and in which group of patients PCR needs to be used more carefully as a surrogate end point in clinical studies. In addition to BRCA1/2 mutation status, it has been discussed whether a family history of $\mathrm{BC}$ and/or ovarian cancer (OC) might serve as a surrogate for a genetically enriched population and play a major role in predicting $\mathrm{PCR}$.

In an analysis of TNBC patients from the GeparSixto trial, patients with a positive family history had a moderately increased pCR rate, but the multivariable analysis showed that family history was not a predictor of $\mathrm{pCR}$ [11]. As there are only a few published studies about this issue, the aim of this study was to analyze whether family history has an impact on pCR overall, particularly in molecular subtypes in addition to commonly known predictors of pCR, and whether the effect of pCR on the longterm prognosis differs between groups with and without a family history of BC or OC.

\section{Patients and Methods}

Study Population

This retrospective observational study included patients with primary BC from the Erlangen Neoadjuvant Study of the Breast (ERNEST-B) who were at least 18 years old and had undergone neoadjuvant chemotherapy between 2001 and 2018, followed by definitive surgery $(n=1,614)$. Information on the following parameters had to be available from the pretreatment assessment: age, tumor size, estrogen receptor (ER) status, progesterone receptor (PgR) status, HER2 receptor status, grading, proliferation status as assessed by Ki-67 staining, and the number of first-degree relatives affected with $\mathrm{BC}$ and/or OC. Patients were excluded for the reasons shown in Figure 1. The final study population consisted of 1,480 patients.

\section{Clinical Data}

Clinical data were collected in a prospective database as part of a continuous quality control process required for compliance with the certification requirements for breast centers in Germany (www. onkozert.de). Patient and tumor characteristics must be documented as well as exact treatment information concerning surgery, radiotherapy, and systemic therapies. Patients are followed up for a period of 10 years. All data are audited annually on site by an external expert review panel. This process ensures quality control of treatment in accordance with the German guidelines and has been reported to improve the prognosis for patients as a consequence of treatment in conformity with the guidelines [16-18].

\section{Systemic Treatments}

Patients mainly received anthracycline/taxane-based chemotherapy, while some received cyclophosphamide/methotrexate/ fluorouracil or other regimens. TNBC patients were partly treated with a platinum/taxane-based regimen. HER2-positive BC patients received additional neoadjuvant and adjuvant anti-HER2 therapy. Hormone receptor-positive $\mathrm{BC}$ patients were treated with an adjuvant antihormone therapy. Treatments were administered in accordance with the standard guidelines in the respective years. Systemic treatments in the study population have been described previously $[3,10,19]$.

\section{Epidemiological Data}

Information on risk factors for BC was collected using an epidemiological questionnaire developed for studies concerned with identifying genetic and nongenetic risk factors and prognostic factors in BC [20-22]. The data collected with the questionnaire were harmonized in order to make the information available to large international consortia and have been previously published [2325]. In this analysis, family history is regarded as positive if the patient had at least 1 first-degree relative with a diagnosis of $\mathrm{BC}$ and/or OC.

\section{Pathology Data}

The histopathological information was directly documented from the original pathology reports, which were reviewed by 2 investigators. Grading, tumor type, ER status, PgR status, HER2 receptor status, and $\mathrm{Ki}-67$ staining were assessed as part of clinical routine testing on formalin-fixed, paraffin-embedded tumor tissue at the time of the initial diagnosis, as described previously [3]. HER2 was positive when immunohistochemical staining indicated a $3+$ result or the tumor showed HER2 amplification, as determined by chromogene in situ hybridization (CISH; ZytoDot, 2C SPEC HER2/CEN17, Zyto Vision Ltd., Bremerhaven, Germany). The immunohistochemical evaluation was quality-controlled and validated in annual round-robin tests. 
Fig. 1. Patient selection. BC, breast cancer; ERNEST-B, Erlangen Neoadjuvant Study Breast; OC, ovarian cancer; $\mathrm{pCR}$, pathological complete response.

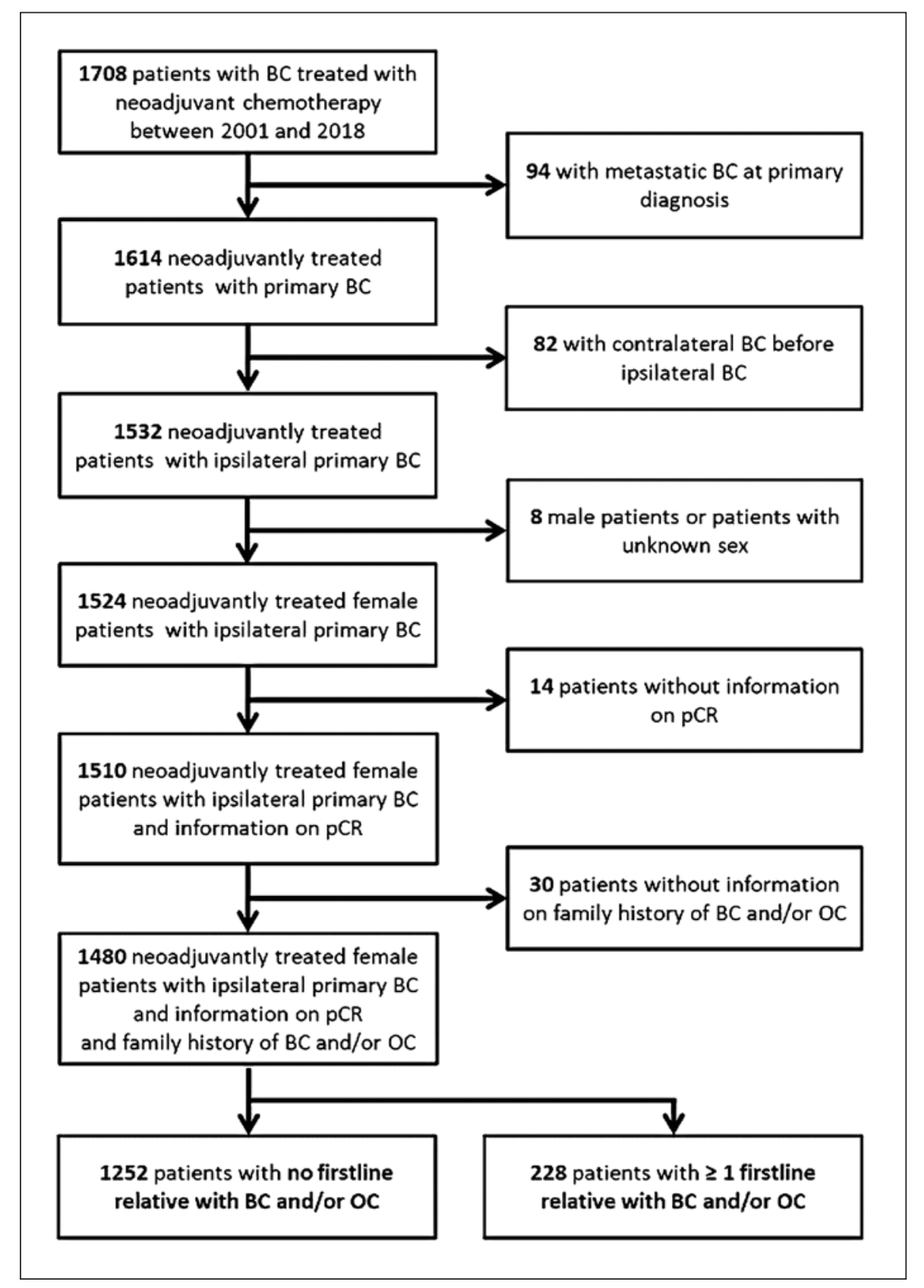

Tumor molecular subtype was defined consistently with the guidelines in the respective years. Luminal A-like tumors were ERpositive or PgR-positive, HER2-negative, and had low Ki-67 values $(<14 \%)$. Luminal B-like tumors were ER-positive or PgR-positive, HER2-negative, and had high Ki-67 values $(\geq 14 \%)$. TNBCs were required to be negative or weakly positive $(\leq 10 \%)$ for ER and $\mathrm{PgR}$ and constantly negative for HER2. All HER2-positive tumors were grouped together, regardless of hormone receptor status [26, 27].

pCR was defined as a complete absence of invasive tumor cells or carcinoma in situ cells from the breast and lymph nodes after chemotherapy at the time of surgery (ypT0; ypN0).

Statistical Analysis

The primary objective was to investigate whether information about a family history of $\mathrm{BC}$ and/or OC has an impact on pCR overall and particularly in molecular subtypes, in addition to other well-known predictive factors. For this purpose, a multiple lo- gistic regression model was fitted with pCR status as a binary outcome (Yes vs. No) and the following predictors: a family history of $\mathrm{BC} / \mathrm{OC}$ (Yes vs. No), age at diagnosis (continuous), body mass index (BMI; continuous), clinical tumor stage (ordinal; cT1 to cT4), tumor type (categorical; ductal, lobular, and other), grade (ordinal; G1 to G3), ER status, PgR status, HER2 status (each categorical; positive vs. negative), and Ki-67 (categorical; high vs. low).

Subsequently, an additional logistic model (the full model) was fitted containing the predictor family history of BC/OC (Yes vs. No), the predictors of the previous basic model, and the interactions between a family history of BC/OC and ER, PgR, HER2, and $\mathrm{Ki}-67$. Both models were compared using the likelihood ratio test. A significant test result indicates that a family history of $\mathrm{BC} / \mathrm{OC}$ influences pCR, either across all patients or at least within 1 of the subgroups defined by the interaction terms. In cases of significance, molecular subtype-specific adjusted odds ratios (ORs) were 
estimated, using the full model. Otherwise, an adjusted overall OR for a family history of $\mathrm{BC} / \mathrm{OC}$ was estimated, using a reduced full model in which the interaction terms were excluded.

DFS was defined as the time from the date of diagnosis to the earliest date of disease progression (local recurrence, invasive contralateral $\mathrm{BC}$, distant metastasis, or death from any cause) or the date of censoring. Patients who were lost to follow-up before the maximum observation period of 10 years, or were disease-free after the maximum observation time, were censored at the last date on which they were known to be disease-free, or at the maximum observation time.

The secondary objective was to study whether the impact of a family history of BC/OC on DFS varied between patients with and without PCR. A Cox regression model was fitted with the predictors described above and additionally pCR (Yes vs. No). Next, another Cox model was fitted containing these predictors and in addition the interaction of $\mathrm{pCR}$ relative to a family history of $\mathrm{BC} / \mathrm{OC}$. The 2 models were compared using the likelihood ratio test. A significant test result means that the impact of a family history of $\mathrm{BC} / \mathrm{OC}$ on DFS is different in patients who achieve a pCR and those who do not. In cases of significance, $\mathrm{pCR}$ status-specific hazard ratios (HRs) for a family history of BC/OC were estimated using the interaction model. Otherwise, an overall $\mathrm{HR}$ for a family history of BC/OC was estimated using the first Cox model described. The proportional hazards assumptions were checked using the Grambsch-Therneau method.

Patients who did not achieve a pCR, or for whom information about family history of BC/OC was lacking, were excluded from both analyses. Missing values for other predictors were imputed, and continuous predictors were used as natural cubic spline functions (as in [28]).

For sensitivity analyses, unadjusted ORs and HRs were estimated using simple logistic and Cox regression models. Survival rates, especially 5 - and 10-year survival rates, were estimated using the Kaplan-Meier product limit method. In addition, analyses were repeated with a family history of $\mathrm{BC}$ (Yes vs. No) as the variable of interest instead of a family history of BC/OC (Yes vs. No), and ORs and HRs are shown.

All of the tests were two-sided, and $p<0.05$ was regarded as statistically significant. Calculations were carried out using the $R$ system for statistical computing (v3.4.1; $R$ Development Core Team, Vienna, Austria, 2017).

\section{Results}

\section{Patient and Tumor Characteristics}

Of the 1,480 patients who were included in this analysis, a total of $228(15.4 \%)$ had a family history including a first-degree relative with BC and/or OC. Of these, 198 $(86.8 \%)$ had a family history of BC and 40 (17.5\%) had a family history of OC. The patient and tumor characteristics of individuals with and without a family history were similar. Patient and tumor characteristics relative to a family history of BC/OC are shown in Table 1.

\section{Family History of BC/OC and $p C R$}

Of 7,880 patients with primary $\mathrm{BC}$ being treated between 2001 and 2018 at the Breast Center of the Erlangen University Hospital, 1,614 (20.5\%) received neoadjuvant chemotherapy as part of ERNEST-B. Of these, 369 (22.9\%)
Table 1. Patient and tumor characteristics relative to a family history of breast cancer and/or ovarian cancer

\begin{tabular}{|c|c|c|c|c|}
\hline \multirow[t]{2}{*}{ Characteristic } & \multicolumn{2}{|c|}{$\begin{array}{l}\text { No family history } \\
(n=1,252)\end{array}$} & \multicolumn{2}{|c|}{$\begin{array}{l}\text { Family history } \\
(n=228)\end{array}$} \\
\hline & $\begin{array}{l}n \text { or } \\
\text { mean }\end{array}$ & $\begin{array}{l}\% \text { or } \\
\mathrm{SD}\end{array}$ & $\begin{array}{l}n \text { or } \\
\text { mean }\end{array}$ & $\begin{array}{l}\% \text { or } \\
\mathrm{SD}\end{array}$ \\
\hline Age, years & 51.6 & 12.1 & 52.8 & 11.5 \\
\hline BMI, $\mathrm{kg} / \mathrm{m}^{2}$ & 25.9 & 5.2 & 26.4 & 5.4 \\
\hline \multicolumn{5}{|l|}{ Tumor stage } \\
\hline cT1 & 272 & 21.7 & 58 & 25.4 \\
\hline cT2 & 789 & 63.0 & 139 & 61.0 \\
\hline cT3 & 65 & 5.2 & 16 & 7.0 \\
\hline cT4 & 126 & 10.1 & 15 & 6.6 \\
\hline \multicolumn{5}{|l|}{ Lymph node stage } \\
\hline $\mathrm{cN} 0$ & 557 & 44.5 & 113 & 49.6 \\
\hline $\mathrm{cN}+$ & 695 & 55.5 & 115 & 50.4 \\
\hline \multicolumn{5}{|l|}{ Tumor type } \\
\hline Ductal & 899 & 71.8 & 157 & 68.9 \\
\hline Lobular & 92 & 7.3 & 23 & 10.1 \\
\hline Other & 261 & 20.8 & 48 & 21.1 \\
\hline \multicolumn{5}{|l|}{ Grade } \\
\hline G1 & 37 & 3.0 & 5 & 2.2 \\
\hline G2 & 462 & 36.9 & 93 & 40.8 \\
\hline G3 & 753 & 60.1 & 130 & 57.0 \\
\hline \multicolumn{5}{|l|}{ ER status } \\
\hline ER- & 399 & 31.9 & 82 & 36.0 \\
\hline ER+ & 853 & 68.1 & 146 & 64.0 \\
\hline \multicolumn{5}{|l|}{ PgR status } \\
\hline PgR- & 724 & 57.8 & 136 & 59.6 \\
\hline PgR+ & 528 & 42.2 & 92 & 40.4 \\
\hline \multicolumn{5}{|l|}{ HER2 status } \\
\hline HER2- & 940 & 75.1 & 179 & 78.5 \\
\hline HER2+ & 312 & 24.9 & 49 & 21.5 \\
\hline \multicolumn{5}{|l|}{ Ki-67 status } \\
\hline Ki67 <14\% & 170 & 13.6 & 26 & 11.4 \\
\hline $\mathrm{Ki} 67 \geq 14 \%$ & 1,082 & 86.4 & 202 & 88.6 \\
\hline \multicolumn{5}{|l|}{ Molecular subtype } \\
\hline Luminal A-like & 141 & 11.3 & 19 & 8.3 \\
\hline Luminal B-like & 524 & 41.9 & 102 & 44.7 \\
\hline HER2-positive & 312 & 24.9 & 49 & 21.5 \\
\hline Triple-negative & 275 & 22.0 & 58 & 25.4 \\
\hline \multicolumn{5}{|l|}{ pCR } \\
\hline No & 946 & 75.6 & 165 & 72.4 \\
\hline Yes & 306 & 24.4 & 63 & 27.6 \\
\hline
\end{tabular}

Mean and SD are shown for continuous characteristics and $n$ and \% for categorical characteristics. BMI, body mass index; ER, estrogen receptor; pCR, pathological complete response; PgR, progesterone receptor.

achieved a pCR. In patients without a family history of BC/OC, 306 of 1,252 (24.4\%) had a pCR. In patients with a family history, 63 of $228(27.6 \%)$ had a pCR. It was not found that a family history of $\mathrm{BC} / \mathrm{OC}$ had an impact on pCR, neither across all patients nor within the molecular subtypes luminal A-like, luminal B-like, HER2-positive, and triple-negative ( $p=0.07$, likelihood ratio test). The adjusted overall OR was 1.23 (95\% confidence interval 


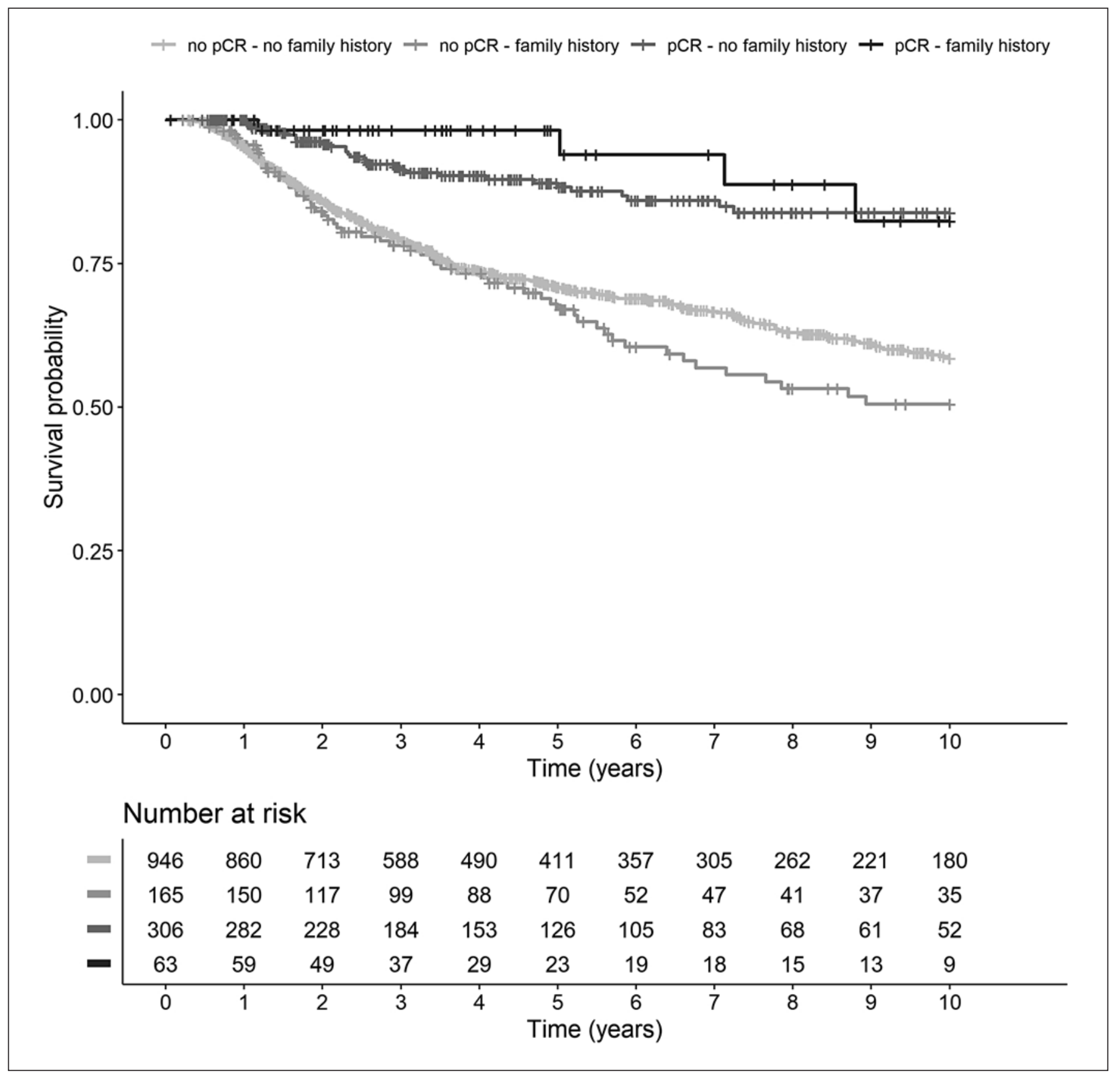

Fig. 2. Kaplan-Meier curves for disease-free survival relative to pathological complete response (pCR) and a family history of breast cancer and/or ovarian cancer.

[CI] $0.85-1.76 ; p=0.27)$; the unadjusted overall OR was 1.18 (95\% CI $0.86-1.62 ; p=0.31)$.

\section{Family History of $B C / O C$ and DFS}

The median follow-up period for DFS was 4.1 years, both for patients with a family history of $\mathrm{BC} / \mathrm{OC}$ and those without. The study did not show different effects of the family history on DFS in patients who achieved a pCR and patients who did not achieve a pCR ( $p=0.15$, likelihood ratio test). Moreover, family history status in gen- eral was not associated with DFS. The adjusted HR for patients with a family history of $\mathrm{BC} / \mathrm{OC}$ versus patients without a family history was 1.15 (95\% CI $0.88-1.52 ; p=$ 0.30 ); the unadjusted HR was 1.12 (95\% CI 0.85-1.46; $p=$ 0.42 ). Kaplan-Meier curves are shown in Figure 2. The 5and 10-year survival rates are presented in Table 2.

Family History of $B C$

Sensitivity analyses with a family history of $\mathrm{BC}$ as the variable of interest, instead of a family history of BC/OC, 
Table 2. Number of events and rates of disease-free survival

\begin{tabular}{lllll}
\hline Subgroup & $\begin{array}{l}\text { Number of } \\
\text { at-risk patients }\end{array}$ & $\begin{array}{l}\text { Number of } \\
\text { events }\end{array}$ & $\begin{array}{l}\text { 5-year DFS } \\
(95 \% \text { CI })\end{array}$ & $\begin{array}{l}\text { 10-year DFS } \\
(95 \% \text { CI })\end{array}$ \\
\hline No pCR and no FH & 946 & 288 & $0.71(0.68-0.74)$ & $0.58(0.55-0.63)$ \\
No pCR and FH & 165 & 59 & $0.67(0.59-0.76)$ & $0.50(0.42-0.61)$ \\
pCR and no FH & 306 & 31 & $0.88(0.84-0.93)$ & $0.84(0.78-0.90)$ \\
pCR and FH & 63 & 4 & $0.98(0.95-1.00)$ & $0.82(0.67-1.00)$ \\
\hline
\end{tabular}

CI, confidence interval; DFS, disease-free survival; FH, a family history of breast and/or ovarian cancer; pCR, pathological complete response.

yielded similar results. The adjusted and unadjusted ORs for a family history of BC were 1.16 (95\% CI 0.79-1.72; $p=0.45)$ and 1.08 (95\% CI 0.77-1.52; $p=0.64)$, respectively. The adjusted and unadjusted HRs for a family history of BC were $1.12(95 \%$ CI $0.84-1.49 ; p=0.45)$ and 1.08 (95\% CI $0.81-1.44 ; p=0.61)$.

\section{Discussion}

This study did not show that a family history of BC/ OC has an impact on pCR, neither across all patients nor within a molecular subtype, in addition to age, BMI, tumor stage, tumor type, grading, hormone receptor status, HER2 status, and Ki-67 proliferation index.

Recently, the effect of family history and $B R C A 1 / 2 \mathrm{mu}-$ tation status on $\mathrm{pCR}$ was reported in a subgroup analysis of TNBC patients from the GeparSixto study. The pCR rate (ypT0; ypN0) was $42.0 \%$ in patients without a family history and $48.2 \%$ in those with a family history. The addition of platinum increased the pCR rate both in patients with a family history and those without, but it did not increase the already high pCR rate in $B R C A 1 / 2$ mutation carriers. In the multivariate analysis, neither $B R C A 1 / 2$ mutation status (OR $1.44 ; 95 \%$ CI $0.54-3.82 ; p=0.46$ ) nor family history (OR $1.04 ; 95 \%$ CI $0.58-1.87 ; p=0.91$ ) was associated with the pCR rate [11]. In the study group overall, the pCR rates were $24.4 \%$ in patients without a family history and $27.6 \%$ in those with at least 1 first-degree relative with $\mathrm{BC}$ and/or OC. The higher $\mathrm{pCR}$ rates recorded in the GeparSixto study might be attributable to the triple-negative subgroup, half of whom were treated with platinum-containing systemic therapy.

It has been suggested that genetic alterations in $B R C A 1 / 2$ or other loci can be found in $<40 \%$ of BC patients with a positive family history $[6,29]$. These include high-penetrance loci such as TP53, PTEN, STK11, CDH1, and $P A L B 2$, and medium-to-low-penetrance loci such as CHEK2, ATM, RAD51D, RAD51C, BARD1, BRIP1, $M S H 6$, and others [29-31]. Recently, in a large genotyping effort, common low-penetrance polymorphisms (sin- gle-nucleotide polymorphisms [SNPs]) have been identified and validated that modify the risk for BC in BRCA1/2 mutation carriers $[32,33]$. In addition, a total of around 170 common SNPs have been reported to influence the risk of BC in unselected populations (summarized in [29, 34]). As many of these genes have a function in DNA damage sensitizing and repair, cell cycle control, and tumor suppression [29-31], genetic alterations may result in a distinct group of BC patients who show a different response to systemic treatments. There may also be other reasons, not conclusively explained, including epigenetic factors, specific behavioral patterns, and other risk factors that could be familial $[34,35]$.

With regard to the prognosis, this study shows that pCR is predictive of DFS in patients with and without a family history of BC/OC. pCR has been associated with a favorable prognosis in several studies $[1,2,6,13,14]$. This finding has also been supported for $B R C A 1 / 2$ mutation carriers in some studies $[10,11,15]$. In contrast, in a cohort of 80 TNBC patients with a known BRCA1 mutation status who were treated with neoadjuvant anthracycline- and taxane-containing chemotherapy, the $\mathrm{pCR}$ rate was higher in patients with a BRCA1 mutation (67 vs. $37 \%$ ). However, pCR was not predictive of the prognosis in BRCA1 mutation carriers, while it was prognostic in patients without a BRCA1 mutation [36]. These results could be due to chance, but an analysis of the GeparQuinto study also reported that pCR was a predictor of DFS in patients without a BRCA1/2 mutation (HR $0.18 ; 95 \%$ CI $0.11-0.31$ ), but not in those with a BRCA1/2 mutation (HR 0.74; 95\% CI 0.32-1.69) [12]. Moreover, a study on 77 heterogeneously treated TNBC patients showed a better prognosis for the 15 BRCA1/2 mutation carriers than for the 62 noncarriers [37]. Together, these data imply that in BRCA1/2 mutation carriers, the prognosis may not be mediated by the response to chemotherapy, but rather by additional factors such as different BRCA1/2 mutation patterns, alterations in other riskmodifying genes, etc. [32, 33, 35]. The question of how BRCA $1 / 2$ mutations have an effect on $\mathrm{pCR}$ and prognosis will remain unsolved until larger-scale studies become 
available, with possibly prospectively collected data from clinical trials.

Independently of pCR status, some studies on $B R C A 1$ mutation carriers have demonstrated a better $[15,38-40]$ or similar prognosis $[38,41,42]$, but 2 meta-analyses suggested poorer survival $[43,44]$. BRCA2 mutation carriers appear to show no difference in comparison with noncarriers $[39,41,43,44]$ or a poorer prognosis $[44,45]$. In addition, large trials have reported a similar long-term prognosis for the whole group of $B R C A 1 / 2$ mutation carriers in comparison with noncarriers [15, 38, 39, 41, 46]. Even fewer data are available regarding the prognosis with other BC susceptibility genes such as PALB2, CHEK2, and others [47-50].

A few studies have also investigated the influence of a positive family history on the overall survival (OS). One study estimated that the 10 -year OS rate was $73 \%$ in patients with sporadic BC, $75 \%$ in intermediate-risk patients, and $82 \%$ in high-risk patients (log-rank $p<0.0001$ ) [40]. Correspondingly, a meta-analysis reported a better OS in BC patients with a first-degree family history of $\mathrm{BC} /$ OC (OR 0.89; 95\% CI 0.83-0.95) [51].

This study has several strengths and limitations. Firstly, it was retrospective, although the data documented in the database are maintained prospectively. One strength of the study was also the quality-controlled assessment of biomarkers such as ER, PgR, HER2, and Ki-67, which have been shown to be of clinical value in previous publications [3]. A limitation was the small sample size of patients with a positive family history and the heterogeneity of tumor types and different treatments. Due to the study's retrospective nature, the analyses of DFS were limited.

\section{Conclusion}

This study did not use BRCA1/2 mutation status, but the surrogate marker for a genetically enriched cohort "family history." Family history of BC/OC was not associated with $\mathrm{pCR}$ after neoadjuvant chemotherapy. The study confirms that pCR influences DFS regardless of family history. As there is growing evidence that $\mathrm{pCR}$ does not have the same impact on prognosis in all patients, it continues to be difficult to identify patients who may benefit more from pCR. It is not unlikely that certain hereditary BCs may show a good response to chemotherapy, while others do not, and that therapy effects may be mediated through different mechanisms.

\section{Statement of Ethics}

Approval for the analyses conducted in the study was received from the ethics committee of the University of Erlangen-Nuremberg. All procedures were in accordance with the ethics standards of the institutional and/or national research committee and the 1964 Helsinki Declaration and its later amendments or comparable standards. Informed consent was obtained from all patients included in the study.

\section{Conflict of Interest Statement}

M.P.L. reports personal fees from Pfizer, Roche, Merck Sharp \& Dohme, Hexal, Novartis, AstraZeneca, Tesaro, Eisai, medac, and Lilly. C.C.H. reports personal fees from Roche. N.N. reports personal fees from Janssen-Cilag, Novartis, and Teva. A. Hartmann reports personal fees from Bristol-Myers Squibb, Roche, Merck Sharp \& Dome, Novartis, AstraZeneca, NanoString, BioNTech, and Janssen-Cilag. P.A.F. reports research grants from Novartis and BioNTech and personal fees from Novartis, Roche, Pfizer, Celgene, Daiichi-Sankyo, TEVA, AstraZeneca, Puma, Eisai, Merck Sharp \& Dohme, and Myelo Therapeutics. P.G. reports personal fees from Novartis, Roche, and PharmaMar. All the other authors declare that they have no conflicts of interest.

\section{Funding Sources}

This research did not receive any specific grant from funding agencies in the public, commercial, or not-for-profit sectors.

\section{Author Contributions}

M.W., P.A.F., and P.G. contributed to conception and design of the study. M.W., A. Hein, S.M.J., M.P.L., C.C.H., J.E., F.H., N.N., C.R.L., R.S.-W., A. Hartmann, M.W.B., P.A.F., and P.G. contributed to the acquisition of clinical data. L.H. performed the statistical analysis. L.H., M.W., P.A.F., and P.G. performed interpretation of data. M.W., P.A.F., and P.G. were involved in drafting the manuscript. All authors gave final approval of the version to be published, revised the manuscript critically and agreed to be accountable for all aspects of the work in ensuring that questions related to the accuracy or integrity of any part of the work are appropriately investigated and resolved.

\section{References}

1 Taran FA, Schneeweiss A, Lux MP, Janni W, Hartkopf AD, Nabieva N, et al. Update Breast Cancer 2018 (Part 1) - Primary Breast Cancer and Biomarkers. Geburtshilfe Frauenheilkd. 2018 Mar;78(3):237-45.

2 Hartkopf AD, Müller V, Wöckel A, Lux MP, Janni W, Nabieva N, et al. Update Breast Cancer 2019 Part 1 - Implementation of Study Re- sults of Novel Study Designs in Clinical Practice in Patients with Early Breast Cancer. Geburtshilfe Frauenheilkd. 2019 Mar;79(3): 256-67.

3 Fasching PA, Heusinger K, Haeberle L, Niklos M, Hein A, Bayer CM, et al. Ki67, chemotherapy response, and prognosis in breast cancer patients receiving neoadju- vant treatment. BMC Cancer. 2011 Nov; 11(1):486.

4 Litton JK, Gonzalez-Angulo AM, Warneke CL, Buzdar AU, Kau SW, Bondy M, et al. Relationship between obesity and pathologic response to neoadjuvant chemotherapy among women with operable breast cancer. J Clin Oncol. 2008 Sep;26(25):4072-7. 
5 von Minckwitz G, Untch M, Nüesch E, Loibl S, Kaufmann M, Kümmel S, et al. Impact of treatment characteristics on response of different breast cancer phenotypes: pooled analysis of the German neo-adjuvant chemotherapy trials. Breast Cancer Res Treat. 2011 Jan; 125(1):145-56.

6 Kolberg HC, Schneeweiss A, Fehm TN, Wöckel A, Huober J, Pontones C, et al. Update Breast Cancer 2019 Part 3 - Current Developments in Early Breast Cancer: Review and Critical Assessment by an International Expert Panel. Geburtshilfe Frauenheilkd. 2019 May;79(5):470-82.

7 Paluch-Shimon S, Friedman E, Berger R, Papa M, Dadiani M, Friedman N, et al. Neo-adjuvant doxorubicin and cyclophosphamide followed by paclitaxel in triple-negative breast cancer among BRCA1 mutation carriers and non-carriers. Breast Cancer Res Treat. 2016 May;157(1):157-65.

8 Byrski T, Gronwald J, Huzarski T, Grzybowska E, Budryk M, Stawicka M, et al. Pathologic complete response rates in young women with BRCA1-positive breast cancers after neoadjuvant chemotherapy. J Clin Oncol. 2010 Jan;28(3):375-9.

9 Narod SA, Huzarski T, Gronwald J, Byrski T, Marczyk E, Cybulski C, et al. Predictors of survival for breast cancer patients with a BRCA1 mutation. Breast Cancer Res Treat. 2018 Apr;168(2):513-21.

10 Wunderle M, Gass P, Häberle L, Flesch VM, Rauh C, Bani MR, et al. BRCA mutations and their influence on pathological complete response and prognosis in a clinical cohort of neoadjuvantly treated breast cancer patients. Breast Cancer Res Treat. 2018 Aug;171(1): 85-94.

11 Hahnen E, Lederer B, Hauke J, Loibl S, Kröber S, Schneeweiss A, et al. Germline Mutation Status, Pathological Complete Response, and Disease-Free Survival in Triple-Negative Breast Cancer: Secondary Analysis of the GeparSixto Randomized Clinical Trial. JAMA Oncol. 2017 Oct;3(10):1378-85.

12 Fasching PA, Loibl S, Hu C, Hart SN, Shimelis H, Moore R, et al. BRCA1/2 Mutations and Bevacizumab in the Neoadjuvant Treatment of Breast Cancer: Response and Prognosis Results in Patients With Triple-Negative Breast Cancer From the GeparQuinto Study. J Clin Oncol. 2018 Aug;36(22):2281-7.

13 von Minckwitz G, Untch M, Blohmer JU, Costa SD, Eidtmann H, Fasching PA, et al. Definition and impact of pathologic complete response on prognosis after neoadjuvant chemotherapy in various intrinsic breast cancer subtypes. J Clin Oncol. 2012 May;30(15): 1796-804.

14 Cortazar P, Zhang L, Untch M, Mehta K, Costantino JP, Wolmark N, et al. Pathological complete response and long-term clinical benefit in breast cancer: the CTNeoBC pooled analysis. Lancet. 2014 Jul;384(9938): 164-72.

15 Arun B, Bayraktar S, Liu DD, Gutierrez Barrera AM, Atchley D, Pusztai L, et al. Response to neoadjuvant systemic therapy for breast cancer in BRCA mutation carriers and noncarriers: a single-institution experience. J Clin Oncol. 2011 Oct;29(28):3739-46.
16 Beckmann MW, Brucker C, Hanf V, Rauh C, Bani MR, Knob S, et al. Quality assured health care in certified breast centers and improvement of the prognosis of breast cancer patients. Onkologie. 2011;34(7):362-7.

17 Wöckel A, Festl J, Stüber T, Brust K, Krockenberger M, Heuschmann PU, et al. Interdisciplinary Screening, Diagnosis, Therapy and Follow-up of Breast Cancer. Guideline of the DGGG and the DKG (S3-Level, AWMF Registry Number 032/045OL, December 2017) Part 2 with Recommendations for the Therapy of Primary, Recurrent and Advanced Breast Cancer. Geburtshilfe Frauenheilkd. 2018 Nov;78(11):1056-88.

18 Wöckel A, Festl J, Stüber T, Brust K, Stangl S, Heuschmann PU, et al. Interdisciplinary Screening, Diagnosis, Therapy and Follow-up of Breast Cancer. Guideline of the DGGG and the DKG (S3-Level, AWMF Registry Number 032/045OL, December 2017) - Part 1 with Recommendations for the Screening, Diagnosis and Therapy of Breast Cancer. Geburtshilfe Frauenheilkd. 2018 Oct;78(10): 927-48.

19 Gass P, Lux MP, Rauh C, Hein A, Bani MR, Fiessler C, et al. Prediction of pathological complete response and prognosis in patients with neoadjuvant treatment for triple-negative breast cancer. BMC Cancer. 2018 Oct;18(1):1051.

20 Fasching PA, Loehberg CR, Strissel PL, Lux MP, Bani MR, Schrauder M, et al. Single nucleotide polymorphisms of the aromatase gene (CYP19A1), HER2/neu status, and prognosis in breast cancer patients. Breast Cancer Res Treat. 2008 Nov; 112(1):89-98.

21 Fasching PA, Weihbrecht S, Haeberle L, Gasparyan A, Villalobos IE, Ma Y, et al. HER2 and TOP2A amplification in a hospital-based cohort of breast cancer patients: associations with patient and tumor characteristics. Breast Cancer Res Treat. 2014 May; 145(1):193-203.

22 Rauh C, Hack CC, Häberle L, Hein A, Engel A, Schrauder MG, et al. Percent Mammographic Density and Dense Area as Risk Factors for Breast Cancer. Geburtshilfe Frauenheilkd. 2012 Aug;72(8):727-33.

23 Michailidou K, Hall P, Gonzalez-Neira A, Ghoussaini M, Dennis J, Milne RL, et al.; Breast and Ovarian Cancer Susceptibility Collaboration; Hereditary Breast and Ovarian Cancer Research Group Netherlands (HEBON); kConFab Investigators; Australian Ovarian Cancer Study Group; GENICA (Gene Environment Interaction and Breast Cancer in Germany) Network. Large-scale genotyping identifies 41 new loci associated with breast cancer risk. Nat Genet. 2013 Apr;45(4):353-61.

24 Bojesen SE, Pooley KA, Johnatty SE, Beesley J, Michailidou K, Tyrer JP, et al.; Australian Cancer Study; Australian Ovarian Cancer Study; Kathleen Cuningham Foundation Consortium for Research into Familial Breast Cancer (kConFab); Gene Environment Interaction and Breast Cancer (GENICA); Swedish Breast Cancer Study (SWE-BRCA); Hereditary Breast and Ovarian Cancer Research Group Netherlands (HEBON); Epidemiological study of BRCA1 \& BRCA2 Mutation Carriers (EMBRACE); Genetic Modifiers of Cancer Risk in BRCA1/2 Mutation Carriers (GEMO). Multiple independent variants at the TERT locus are associated with telomere length and risks of breast and ovarian cancer. Nat Genet. 2013 Apr;45(4):371-84.

25 Fasching PA, Pharoah PD, Cox A, Nevanlinna H, Bojesen SE, Karn T, et al.; kConFab Investigators. The role of genetic breast cancer susceptibility variants as prognostic factors. Hum Mol Genet. 2012 Sep;21(17):3926-39.

26 Hammond ME, Hayes DF, Dowsett M, Allred DC, Hagerty KL, Badve S, et al. American Society of Clinical Oncology/College of American Pathologists guideline recommendations for immunohistochemical testing of estrogen and progesterone receptors in breast cancer. J Clin Oncol. 2010 Jun;28(16):2784-95.

27 Goldhirsch A, Ingle JN, Gelber RD, Coates AS, Thürlimann B, Senn HJ; Panel members. Thresholds for therapies: highlights of the St Gallen International Expert Consensus on the primary therapy of early breast cancer 2009. Ann Oncol. 2009 Aug;20(8):1319-29.

28 Salmen J, Neugebauer J, Fasching PA, Haeberle L, Huober J, Wöckel A, et al. Pooled analysis of the prognostic relevance of progesterone receptor status in five German cohort studies. Breast Cancer Res Treat. 2014 Nov; 148(1):143-51.

29 Wunderle M, Olmes G, Nabieva N, Häberle L, Jud SM, Hein A, et al. Risk, prediction and prevention of hereditary breast cancer - large scale genomic studies in the times of big and smart data. Geburtshilfe Frauenheilkd. 2018 May;78(5):481-92.

30 Couch FJ, Hart SN, Sharma P, Toland AE, Wang X, Miron P, et al. Inherited mutations in 17 breast cancer susceptibility genes among a large triple-negative breast cancer cohort unselected for family history of breast cancer. J Clin Oncol. 2015 Feb;33(4):304-11.

31 Couch FJ, Shimelis H, Hu C, Hart SN, Polley EC, Na J, et al. Associations Between Cancer Predisposition Testing Panel Genes and Breast Cancer. JAMA Oncol. 2017 Sep;3(9): 1190-6.

32 Couch FJ, Wang X, McGuffog L, Lee A, Olswold C, Kuchenbaecker KB, et al.; kConFab Investigators; SWE-BRCA; Ontario Cancer Genetics Network; HEBON; EMBRACE; GEMO Study Collaborators; BCFR; CIMBA. Genome-wide association study in BRCA1 mutation carriers identifies novel loci associated with breast and ovarian cancer risk. PLoS Genet. 2013;9(3):e1003212.

33 Friebel TM, Domchek SM, Rebbeck TR. Modifiers of cancer risk in BRCA1 and BRCA2 mutation carriers: systematic review and meta-analysis. J Natl Cancer Inst. 2014 Jun;106(6):dju091.

34 Fasching PA, Ekici AB, Wachter DL, Hein A, Bayer CM, Häberle L, et al. Breast Cancer Risk - From Genetics to Molecular Understanding of Pathogenesis. Geburtshilfe Frauenheilkd. 2013 Dec;73(12):1228-35.

35 Couch FJ, Nathanson KL, Offit K. Two decades after BRCA: setting paradigms in personalized cancer care and prevention. Science. 2014 Mar;343(6178):1466-70.

36 Paluch-Shimon S, Friedman E, Berger R, Papa MZ, Dadiani M, Friedman N, et al. Does pathologic complete response predict for outcome in BRCA mutation carriers with triple-negative breast cancer? J Clin Oncol. 2014;32:5s.
Influence of a Family History of BC/OC on pCR and Prognosis in BC Patients 
37 Gonzalez-Angulo AM, Timms KM, Liu S, Chen H, Litton JK, Potter J, et al. Incidence and outcome of BRCA mutations in unselected patients with triple receptor-negative breast cancer. Clin Cancer Res. 2011 Mar; 17(5):1082-9.

38 Copson ER, Maishman TC, Tapper WJ, Cutress RI, Greville-Heygate S, Altman DG, et al. Germline BRCA mutation and outcome in young-onset breast cancer (POSH): a prospective cohort study. Lancet Oncol. 2018 Feb;19(2):169-80.

39 Rennert G, Bisland-Naggan S, Barnett-Griness O, Bar-Joseph N, Zhang S, Rennert HS, et al. Clinical outcomes of breast cancer in carriers of BRCA1 and BRCA2 mutations. $\mathrm{N}$ Engl J Med. 2007 Jul;357(2):115-23.

40 Cortesi L, Masini C, Cirilli C, Medici V, Marchi I, Cavazzini G, et al. Favourable ten-year overall survival in a Caucasian population with high probability of hereditary breast cancer. BMC Cancer. 2010 Mar;10(1):90.

41 Goodwin PJ, Phillips KA, West DW, Ennis M, Hopper JL, John EM, et al. Breast cancer prognosis in BRCA1 and BRCA2 mutation carriers: an International Prospective Breast Cancer Family Registry population-based cohort study. J Clin Oncol. 2012 Jan;30(1):19-26.
42 Huzarski T, Byrski T, Gronwald J, Górski B, Domagala P, Cybulski C, et al. Ten-year survival in patients with BRCA1-negative and BRCA1-positive breast cancer. J Clin Oncol. 2013 Sep;31(26):3191-6.

43 Zhong Q, Peng HL, Zhao X, Zhang L, Hwang WT. Effects of BRCA1- and BRCA2-related mutations on ovarian and breast cancer survival: a meta-analysis. Clin Cancer Res. 2015 Jan;21(1):211-20.

44 Baretta Z, Mocellin S, Goldin E, Olopade OI, Huo D. Effect of BRCA germline mutations on breast cancer prognosis: A systematic review and meta-analysis. Medicine (Baltimore). 2016 Oct;95(40):e4975.

45 Wang YA, Jian JW, Hung CF, Peng HP, Yang $\mathrm{CF}$, Cheng HS, et al. Germline breast cancer susceptibility gene mutations and breast cancer outcomes. BMC Cancer. 2018 Mar;18(1): 315.

46 van den Broek AJ, Schmidt MK, van 't Veer LJ, Tollenaar RA, van Leeuwen FE. Worse breast cancer prognosis of BRCA1/BRCA2 mutation carriers: what's the evidence? A systematic review with meta-analysis. PLoS One. 2015 Mar; 10(3):e0120189.
47 Cybulski C, Kluźniak W, Huzarski T, Wokołorczyk D, Kashyap A, Jakubowska A, et al.; Polish Hereditary Breast Cancer Consortium. Clinical outcomes in women with breast cancer and a PALB2 mutation: a prospective cohort analysis. Lancet Oncol. 2015 Jun;16(6):638-44.

48 Huzarski T, Cybulski C, Wokolorczyk D, Jakubowska A, Byrski T, Gronwald J, et al Survival from breast cancer in patients with CHEK2 mutations. Breast Cancer Res Treat. 2014 Apr;144(2):397-403.

49 Weischer M, Nordestgaard BG, Pharoah P Bolla MK, Nevanlinna H, Van't Veer LJ, et al. CHEK2*1100delC heterozygosity in women with breast cancer associated with early death, breast cancer-specific death, and increased risk of a second breast cancer. J Clin Oncol. 2012 Dec;30(35):4308-16.

50 Liu C, Chang H, Li XH, Qi YF, Wang JO, Zhang Y, et al. Network Meta-Analysis on the Effects of DNA Damage Response-Related Gene Mutations on Overall Survival of Breast Cancer Based on TCGA Database. J Cell Biochem. 2017 Dec;118(12):4728-34.

51 Song JL, Chen C, Yuan JP, Sun SR. The association between prognosis of breast cancer and first-degree family history of breast or ovarian cancer: a systematic review and metaanalysis. Fam Cancer. 2017 Jul;16(3):339-49. 